\title{
PERBANDINGAN MODEL AR(1), ARMA (1,1), DAN ARIMA (1,1,1) PADA PREDIKSI TINGGI MUKA AIR SUNGAI BENGAWAN SOLO PADA POS PEMANTAUAN JURUG
}

\author{
Retno Tri Vulandari ${ }^{1}$, Tika Andarasni Parwitasari ${ }^{2}$ \\ ${ }^{1,2}$ Program Studi Teknik Informatika, STMIK Sinar Nusantara Surakarta \\ retnotv@sinus.ac.id ${ }^{1}$, tika@ sinus.ac.id ${ }^{2}$
}

\begin{abstract}
ABSTRAK
Suatu aliran sungai menentukan prediksi debit sungai sulit, biasanya nilai yang digunakan sebagai patokan adalah hasil pantauan tinggi muka air. Pada bulan Juli 2016, luapan sungai Bengawan Solo mengakibatkan banjir di kawasan Solo Timur. Hal ini disebabkan karena tinggi muka air pada pos pemantauan Jurug menembus level 10. Oleh karena itu prediksi nilai tinggi muka air diperlukan sebagai upaya peringatan dini banjir. Pengukuran tinggi muka air sungai Bengawan Solo pada setiap pos pemantauan dilakukan setiap hari. Data tinggi muka air merupakan data runtun waktu. Salah satu metode peramalan data runtun waktu adalah Autoregressive Integrated Moving Average (ARIMA), model ini memiliki asumsi homoskedastisitas atau variansi eror tetap. Tetapi apabila variansi eror berubah-ubah maka model yang digunakan adalah model Generalized Autoregressive Conditional Heteroscedasticity (GARCH). Penelitian ini menggunakan 60 data dari bulan Januari - Februari 2017. Data tersebut terbukti stasioner berdasarkan nilai ADF 0,0036, oleh karena itu model ARIMA dapat digunakan. Berdasarkan pola korelogram, ACF dan PACF terpotong setelah lag pertama, hal ini menunjukan tinggi muka air sungai periode tersebut dapat dimodelkan dengan $\operatorname{AR}(1)$, ARMA(1,1), dan ARIMA(1,1,1).Berdasarkan perbandingan nilai MAPE ketiga model nilai terendah adalah model $\operatorname{ARMA}(1,1)$, yaitu 0,668384 yang artinya tingkat kesalahan terhadap prediksi model ARMA $(1,1)$ adalah $66,8384 \%$. Begitu hal nya dengan nilai MSE ketiga model, nilai terendah pada model $\operatorname{ARMA}(1,1)$ yaitu 0,7729 artinya memiliki variansi model yang lebih kecil, mampu memberikan hasil yang lebih konsisten dibandingkan model $\operatorname{AR}(1)$ dan $\operatorname{ARIMA}(1,1,1)$ yaitu 1,060288 dan 0,996585 .
\end{abstract}

Kata kunci: model ARIMA, tinggi muka air sungai Bengawan Solo

\begin{abstract}
A river flow determines the prediction of river flow is difficult, usually the value used as a benchmark is the result of monitoring the water level. In July 2016, the flood of Bengawan Solo river caused flood in East Solo area. This is because the water level at the monitoring station Jurug penetrate level 10. Therefore, the prediction of water level is needed as an early warning effort of flood. The measurement of the water level of the Bengawan Solo River at each monitoring post is done daily. The water level data is the time series data. One method of forecasting time series data is Autoregressive Integrated Moving Average (ARIMA), this model has the assumption of homoscedasticity or fixed error variance. But if the variance of the error varies then the model used is the Generalized Autoregressive Conditional Heteroscedasticity (GARCH) model. This study used 60 data from January to February 2017. The data proved stationary based on ADF value 0.0036, therefore ARIMA model can be used. Based on the corelogram pattern, ACF and PACF are cut off after the first lag, this shows that the river water level of the period can be modeled with AR (1), ARMA $(1,1)$, and ARIMA $(1,1,1)$. Based on the comparison of MAPE values, the three models of the lowest value are ARMA (1.1) model, that is 0.668384 which means the error rate on the prediction of ARMA model (1.1) is $66.8384 \%$. So the thing with the MSE value of the three models, the lowest value in the ARMA model (1.1) that is 0.7729 means having a smaller model variance, able to give more consistent results than $\operatorname{AR}(1)$ and $\operatorname{ARIMA}(1.1,1)$ that is 1.060288 and 0.996585 .
\end{abstract}




\section{Retno Tri Vulandari1, Tika Andarasni Parwitasari²}

Keywords: ARIMA model, water level of Bengawan Solo river

\section{PENDAHULUAN}

Aliran sungai merupakan informasi yang paling penting bagi pengelola sumber daya air. Debit puncak (banjir) diperlukan untuk merancang bangunan pengendali banjir. Sementara data debit aliran kecil diperlukan untuk perencanaan alokasi air untuk berbagai macam keperluan, terutama pada musim kemarau panjang. Debit aliran rata-rata tahunan dapat memberikan gambaran potensi sumber daya air yang dapat dimanfaatkan dari suatu daerah aliran sungai. Debit adalah laju aliran air yang melewati suatu penampang melintang sungai per satuan waktu. Dalam laporan-laporan teknis, debit aliran biasanya ditunjukkan dalam bentuk hidrograf aliran. Hidrograf aliran adalah suatu perilaku debit sebagai respon adanya perubahan karakteristik biogeofisik yang terjadi karena kegiatan pengelolaan DAS dan adanya fluktuasi musiman atau tahunan seperti perubahan iklim lokal (Mahmuda, 2012).

Intensitas hujan tahunan di daerah aliran sungai (DAS) Bengawan Solo mengakibatkan debit aliran sungai besar di beberapa anak sungai. Debit aliran sungai yang besar mengakibatkan tinggi muka air di beberapa pos bendungan meningkat. Pengukuran tinggi muka air pada tiap bendungan. Hal ini dibutuhkan untuk mengantisipasi banjir. Pada akhir tahun 2016 di kawasan Solo timur terjadi banjir yang diakibatkan oleh meluapnya air sungai Bengawan Solo, pada pos pemantauan Jurug melebihi level 10. Terdapat 10 Kelurahan di bagian Solo timur tergenangi oleh banjir. Oleh karena itu diperlukan suatu model yang dapat digunakan untuk memprediksi tinggi muka air, agar dapat dilakukan peringatan dini bahaya banjir. Tinggi muka air pada pos pemantauan Jurug merupakan data runtun waktu yang diukur tiap hari.

Data runtun waktu dapat disusun dengan model stasioner, seperti Autoregressive Integrated Moving Average (ARIMA). Model ini dapat diidentifikasi dengan Autocorelation Function (ACF) dan Partial Autocorelation Function (PACF). Model ARIMA memiliki asumsi homoskedastisitas atau variansi eror tetap. Tetapi jika data runtun waktu tinggi muka air memiliki variansi eror berubah-ubah setiap saat atau terjadi heteroskedastisitas (Setiawan, 2013). 


\section{Perbandingan Model AR(1), ARMA (1,1), dan ARIMA (1,1,1) pada Prediksi Tinggi Muka Air Sungai Bengawan Solo pada Pos Pemantauan Jurug}

\section{TINJAUAN PUSTAKA}

Floros (2005) menjelaskan bahwa ARMA merupakan bentuk model runtun waktu linear yang berusaha untuk mengidentifikasikan persamaandengan hanya menggunakan nilai masa lalunya atau kombinasi nilaimasa lalu dan eror masa lalunya. Model ARMA mengandung dua komponen yaitumodel Autoregressive (AR) dan Moving Average (MA).Berikut adalah model stasioner menurut Cryer (Vulandari, 2014).

1. Autoregressive (AR)

Autoregressive (AR) adalah model rata-rata yang menggambarkan suatu pengamatan pada waktu $t$ dipengaruhi pada nilai-nilai pengamatan sepanjang $p$ periode sebelumnya. Bentuk umum model autoregressive orde padalah

$$
Y_{t}=\phi_{1} Y_{t-1}+\phi_{2} Y_{t-2}+\cdots+\phi_{p} Y_{t-p}+e_{t}
$$

\section{Model Autoregressive Orde (p) atau AR(1)}

Model AR(1) adalah besarnya nilai-nilai pengamatan pada waktu $t$ dipengaruhi oleh nilai-nilai pengamatan sepanjang 1 periode sebelumnya, berdasarkan persamaan (2.1). AR(1) didefinisikan sebagai berikut

$$
Y_{t}=\phi_{1} Y_{t-1}+e_{t}
$$

Model AR(1) dengan $e_{t} \sim W N\left(\mu_{e}, \sigma_{e}^{2}\right)$. Model AR(1) merupakan model stasioner. Suatu proses dikatakan stasioner jika tidak dipengaruhi pada nilai $t$.

$$
\begin{gathered}
Y_{t}=\phi_{1} Y_{t-1}+e_{t} \\
Y_{t-1}=\phi_{1} Y_{t-2}+e_{t-1} \\
Y_{t-2}=\phi_{1} Y_{t-3}+e_{t-2} \\
Y_{t-3}=\phi_{1} Y_{t-4}+e_{t-3} \\
Y_{t}=e_{t}+\phi_{1} e_{t-1}+\phi_{1}^{2} e_{t-2}+\cdots+\phi_{1}^{k} e_{t-k}+\cdots+\phi_{1}^{t-1} e_{1}
\end{gathered}
$$

Mean model autoregresi orde 1 diperoleh sebagai berikut

$$
E\left(Y_{t}\right)=\frac{\mu_{e}\left(1-\phi_{1}^{t}\right)}{\left(1-\phi_{1}\right)}
$$

Untuk $t \rightarrow \infty$ dan $\left|\phi_{1}\right|<1$ maka 


\section{Retno Tri Vulandari1, Tika Andarasni Parwitasari²}

$$
E\left(Y_{t}\right)=\frac{\mu_{e}}{\left(1-\phi_{1}\right)}
$$

Variansi model autoregresi orde 1 diperoleh sebagai berikut

$$
\operatorname{Var}\left(Y_{t}\right)=\frac{\sigma_{e}^{2}\left(1-\phi_{1}^{2 t}\right)}{\left(1-\phi_{1}^{2}\right)}
$$

Untuk $t \rightarrow \infty$ dan $\left|\phi_{1}\right|<1$ maka

$$
\operatorname{Var}\left(Y_{t}\right)=\frac{\sigma_{e}^{2}}{\left(1-\phi_{1}^{2}\right)}
$$

Kovariansi model AR(1) untuk $k=1$ diperoleh sebagai berikut

$$
\operatorname{Cov}\left(Y_{t} Y_{t-1}\right)=\frac{\phi_{1} \sigma_{e}^{2}\left(1-\phi_{1}^{2 t}\right)}{\left(1-\phi_{1}^{2}\right)}
$$

Untuk $t \rightarrow \infty$ dan $\left|\phi_{1}\right|<1$ maka

$$
\gamma_{1}=\frac{\phi_{1} \sigma_{e}^{2}}{\left(1-\phi_{1}^{2}\right)}
$$

kemudian secara umum untuk $k=p$ diperoleh $\gamma_{p}=\frac{\phi_{1}^{p} \sigma_{e}^{2}}{\left(1-\phi_{1}^{2}\right)}$. Autokorelasi (ACF) diperoleh $\rho_{p}=\phi_{1}^{p}$ sehingga diperoleh grafik ACF sebagai berikut

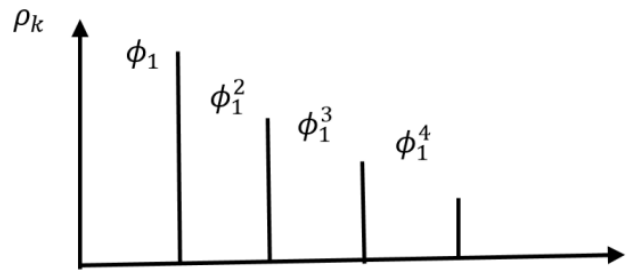

(a) $0<\phi_{1}<1$

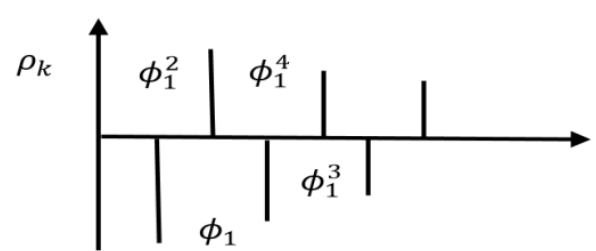

(b) $-1<\phi_{1}<0$

Gambar 1. Grafik ACF Model AR

Berdasarkan Gambar 1 terlihat grafik ACF untuk $0<\phi_{1}<1$ turun cepat secara eksponensial dan untuk $-1<\phi_{1}<0$ turun cepat secara sinusoidal.

2. Autoregressive Moving Average (ARMA)

Autoregressive Moving Average (ARMA) adalah gabungan antara AR dan MA, berikut adalah model umum $\operatorname{ARMA}(p, q)$.

$$
Y_{t}=\phi_{1} Y_{t-1}+\phi_{2} Y_{t-2}+\cdots+\phi_{p} Y_{t-p}+e_{t}-\theta_{1} e_{t-1}-\theta_{2} e_{t-2}-\cdots-\theta_{q} e_{t-q}
$$

\section{$\operatorname{ARMA}(1,1)$}

$\operatorname{ARMA}(1,1)$ adalah proses autoregresif orde 1 dan proses moving average orde 1 sebagai berikut 


$$
Y_{t}=\phi Y_{t-1}+e_{t}-\theta e_{t-1}
$$

sehingga diperoleh fungsi autokovariansi sebagai berikut untuk $k=0$ diperoleh

$$
E\left(Y_{t} Y_{t}\right)=\gamma_{0}=\phi \gamma_{1}+\sigma_{e}^{2}-\theta(\phi-\theta) \sigma_{e}^{2}
$$

untuk $k=1$ diperoleh

$$
E\left(Y_{t} Y_{t-1}\right)=\gamma_{1}=\phi \gamma_{0}-\theta \sigma_{e}^{2}
$$

dengan substitusi Persamaan (2.3) ke Persamaan (2.2) diperoleh

$$
\gamma_{0}=\frac{\left(1-2 \theta \phi+\theta^{2}\right)}{\left(1-\phi^{2}\right)} \sigma_{e}^{2} \operatorname{dan} \gamma_{1}=\frac{(1-\theta \phi)(\phi-\theta)}{\left(1-\phi^{2}\right)} \sigma_{e}^{2}
$$

untuk $k=2$, diperoleh fungsi autokovariansi

$$
\gamma_{2}=\frac{(1-\theta \phi)(\phi-\theta)}{\left(1-\phi^{2}\right)} \phi \sigma_{e}^{2}
$$

untuk $k=k$ diperoleh

$$
\gamma_{k}=\frac{(1-\theta \phi)(\phi-\theta)}{\left(1-\phi^{2}\right)} \phi^{k-1} \sigma_{e}^{2}
$$

Sedangkan fungsi autokorelasi, untuk $k=1$

$$
\rho_{1}=\frac{\gamma_{1}}{\gamma_{0}}=\frac{(1-\theta \phi)(\phi-\theta)}{1-2 \theta \phi+\theta^{2}}
$$

untuk $k=2$

$$
\rho_{2}=\frac{\gamma_{2}}{\gamma_{0}}=\frac{(1-\theta \phi)(\phi-\theta) \phi}{1-2 \theta \phi+\theta^{2}}
$$

untuk $k=k$

$$
\rho_{k}=\frac{\gamma_{k}}{\gamma_{0}}=\frac{(1-\theta \phi)(\phi-\theta) \phi^{k-1}}{1-2 \theta \phi+\theta^{2}}
$$

\section{METODE PENELITIAN}

\section{A. Prosedur Pengolahan Data}

Dalam penelitian ini prosedur pengolahan data yang digunakan di antaranya:

1. Pengumpulan Data

Data-data yang diperlukan dalam penelitian ini berupa data time series dan hasil pengukuran yaitu data tinggi muka air pada pos pemantauan Jurug tahun 2017-2018 


\section{Retno Tri Vulandari1, Tika Andarasni Parwitasari²}

2. Pengolahan Data Input

Sebelum dilakukan analisis dengan metode ARIMA-GARCH maka dilakukan identifikasi data dengan plot data asli untuk mengetahui pola sebaran data, kemudian dilakukan uji stasioneritas karena model ARIMA hanya dapat digunakan oleh data stasioner.

3. Pembagian Data (Load Data)

Pembagian data terdiri data testing yaitu 10 data yang diambil secara acak, data training yaitu tinggi muka air sungai Bengawan Solo tahun 2017.

\section{B. Kerangka Pikir}

Berikut adalah langkah-langkah operasional untuk mencapai tujuan penelitian.

1. Membuat plot data untuk mengetahui pola sebaran data

2. Melakukan uji stasioneritas menggunakan uji akar unit, jika data stasioner maka data langsung dapat dimodelkan.

3. Jika data tidak stasioner, maka dilakukan transformasi $\ln$. Kemudian melakukan uji akar unit kembali.

4. Setelah data stasioner maka dilakukan identifikasi model dengan menggunakan plot ACF dan PACF. Kemudian memberikan kesimpulan dari model stasioner data tersebut dengan menentukan besarnya parameter.

5. Setelah model stasioner terbentukkemudian dilakukan uji diagnostik pada eror yang dihasilkan oleh model tersebut. Eror adalah selisih data prediksi dengan data sebenarnya.

6. Jika asumsi homogenitas variansi tidak terpenuhi, maka artinya data tersebut memiliki variansi eror yang berubah-ubah.

7. Melakukan pemodelan untuk koreksi variansi erornya menggunakan GARCH.

8. Melakukan tahapan simulasi tersebut dengan menggunakanMATLAB.

Langkah-langkah tersebut dapat dilihat dengan jelas pada Gambar 2. 
Perbandingan Model AR(1), ARMA (1,1), dan ARIMA (1,1,1) pada Prediksi Tinggi Muka Air Sungai Bengawan Solo pada Pos Pemantauan Jurug

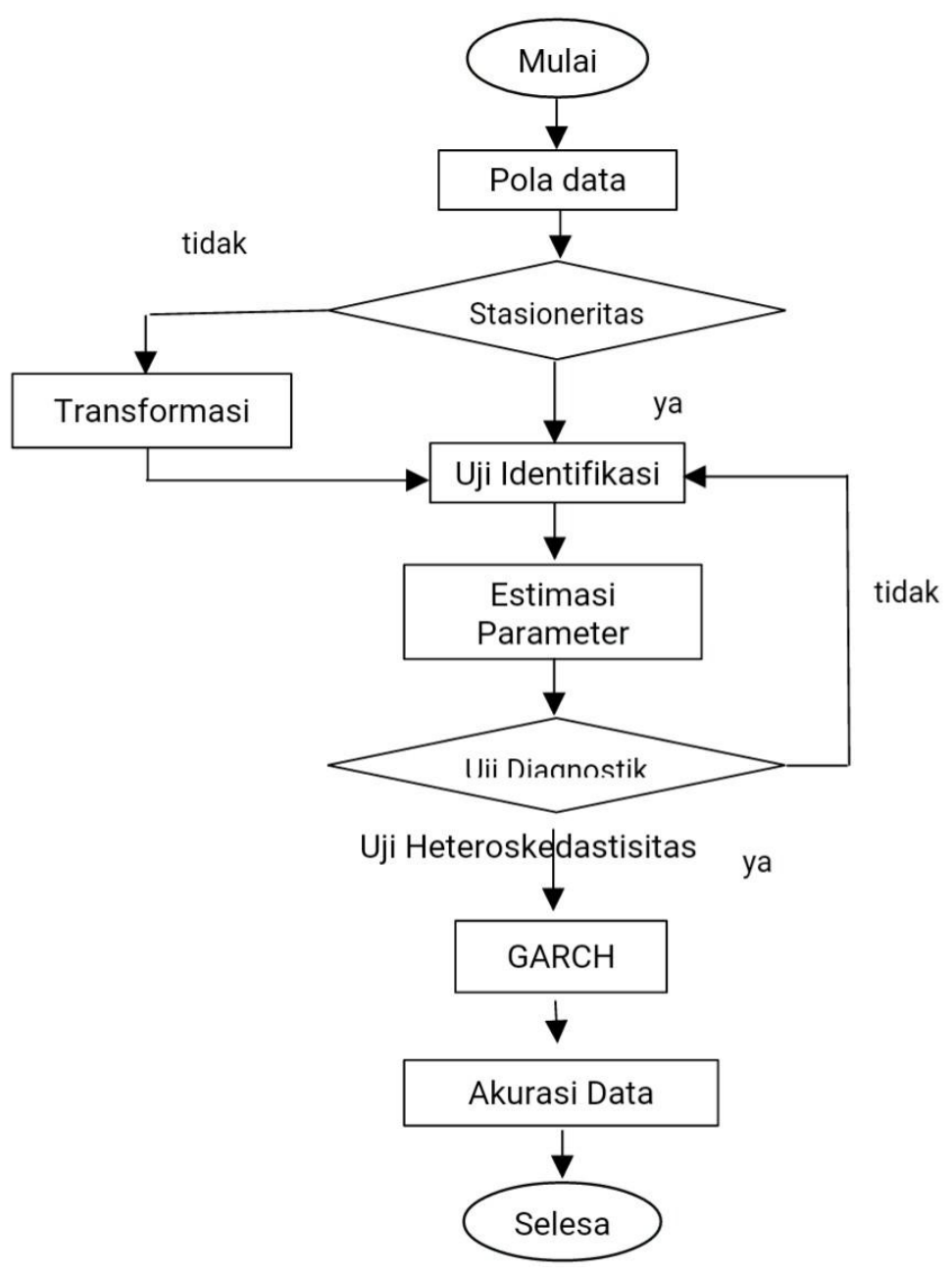

Gambar 2. Kerangka Pikir Penelitian

\section{HASIL PENELITIAN DAN PEMBAHASAN}

\section{Deskripsi dan Pola Data}

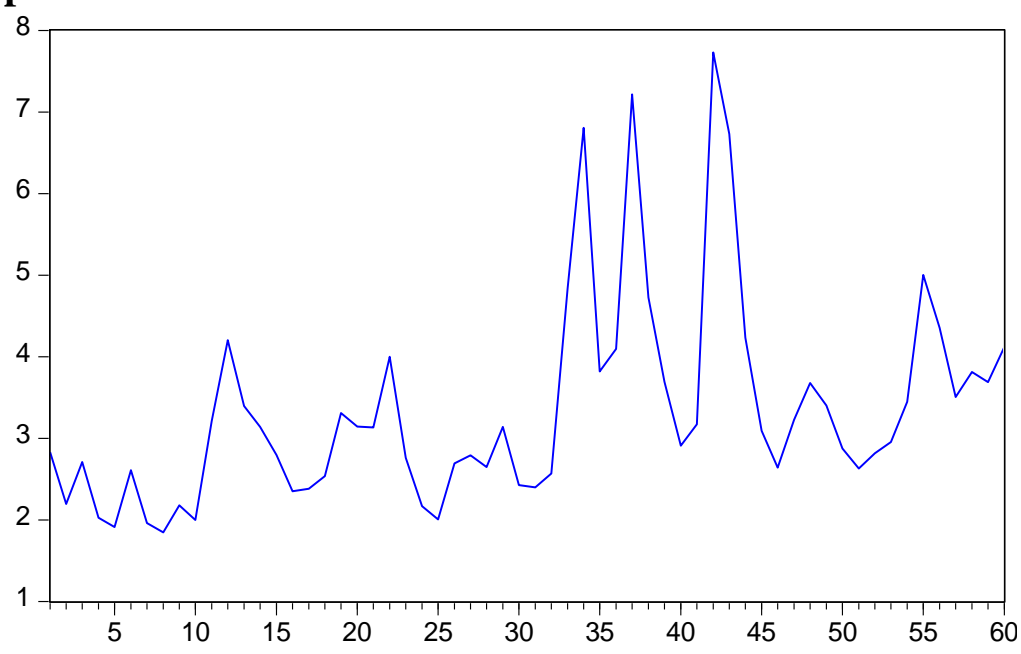

Gambar 3. Grafik Tinggi Muka Air Sungai Bengawan Solo 


\section{Retno Tri Vulandari1, Tika Andarasni Parwitasari²}

Berdasarkan metode penelitian yang telah dirancang, maka langkah pertama yang dilakukan adalah deskripsi data. Gambar 3 menunjukkan data tinggi muka air stasioner dalam rata-rata tetapi variansi tidak konstan. Hal ini diperkuat menggunakan uji stasioner unit root. Nilai probabilitas Augmented Dickey-Fuller (ADF) adalah 0,0036. Nilai probabilitas tersebut lebih kecil dari tingkat signifikansi $\alpha=0,05$. Hal ini juga dapat dibuktikan dari nilai statistik $t,|t|_{T M A}=$ $2,911730>t_{(0,05 ; 59)}=-1,671$, artinya $H_{0}$ berhasil ditolak yang menunjukkan data tidak memiliki akar unit maka data stasioner. Hasil ini dapat dilihat pada Tabel 1. Karena terbukti stasioner terhadap rata-rata maka sebelum memodelkan variansinya, dilakukan model rata-rata terlebih dahulu.

Tabel 1.Uji Stasioner

\begin{tabular}{|c|c|c|c|}
\hline \multicolumn{2}{|c|}{ Null Hypothesis: TMA has a unit root } & \multirow{2}{*}{$\frac{\text { t-Statistic }}{-3,906148}$} & \multirow{2}{*}{$\frac{\text { Prob. }^{*}}{0,0036}$} \\
\hline Augmented Dickey & est statistic & & \\
\hline Test critical values: & $\begin{array}{c}1 \% \text { level } \\
5 \% \text { level } \\
10 \% \text { level }\end{array}$ & $\begin{array}{l}-3,546099 \\
-2,911730 \\
-2,593551\end{array}$ & \\
\hline
\end{tabular}

\section{Identifikasi Model Stasioner Rata-rata}

Pemodelan rata-rata bersyarat dari data stasioner dapat menggunakan ARMA. Untuk mengidentifikasi model ARMA digunakan ACF dan PACF seperti yang terlihat pada Gambar 4. Nilai ACF dan PACF terputus setelah lag pertama, maka model rata-rata bersyarat yang digunakan adalah ARMA(1)

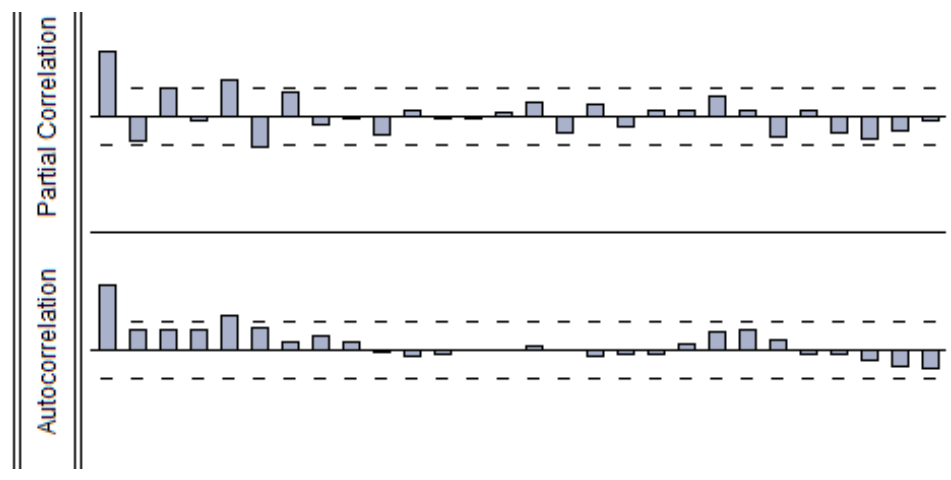

Gambar 4. ACF dan PACF 


\section{Estimasi Parameter Model}

Untuk selanjutnya perhitungan estimasi parameter model stasioner AR(1), $\operatorname{ARMA}(1,1)$, dan ARIMA(1,1,1) diperoleh hasil seperti pada Tabel 2.

Tabel 2. AR(1), ARMA (1,1), dan ARIMA $(1,1,1)$

\begin{tabular}{ccrr}
\hline Variable & AR $(1)$ & ARMA $(1,1)$ & ARIMA $(1,1,1)$ \\
\hline C & 3,382625 & 3.376777 & 0.035659 \\
AR(1) & 0,575876 & 0.075557 & 0.481637 \\
MA(1) & & 0.948131 & -0.999975 \\
\hline
\end{tabular}

Berdasarkan Tabel 2 diperoleh estimasi parameter untuk AR(1) sebagai berikut $\widehat{\phi}_{1}=0,575876$ dan nilai intersep 3,382625sehingga diperoleh model AR(1) berikut

$$
Y_{t}=0,575876 Y_{t-1}+3,382625+e_{t}
$$

dengan $Y_{t}$ adalah tinggi muka air pada waktu dan $e_{t}$ adalah eror yang dihasilkan model AR (1) pada waktu .

Berdasarkan Tabel 2 diperoleh estimasi parameter untuk $\operatorname{ARMA}(1,1)$ sebagai berikut $\widehat{\phi}_{1}=0,075557, \widehat{\theta}_{1}=0,0,948131$ dan nilai intersep 3,376777 sehingga diperoleh model ARMA $(1,1)$ berikut

$$
Y_{t}=0,075557 Y_{t-1}+3,376777+e_{t}-0,0,948131 e_{t-1}
$$

dengan $Y_{t}$ adalah tinggi muka air pada waktu $t$ dan $e_{t}$ adalah eror yang dihasilkan model ARMA $(1,1)$ pada waktu $t$.

\section{Perbandingan Model}

Perbandingan model berdasarkan nilai MAPE dan nilai MSE yang merupakan perbandingan nilai actual dengan nilai prediksi, nilai tersebut dapat dilihat pada Tabel 3.

Tabel 3. Perbandingan Model

\begin{tabular}{ccrr}
\hline Variable & AR(1) & ARMA $(1,1)$ & ARIMA(1,1,1) \\
\hline MAPE & 0,692167 & 0,668384 & 0,690451 \\
MSE & 1,060288 & 0,772956 & 0,996585 \\
\hline
\end{tabular}


Berdasarkan Tabel 3 diperoleh nilai MSE dan MAPE terendah adalah $\operatorname{ARMA}(1,1)$, sehingga dapat disimpulkan untuk periode Januari - Februari 2017, model yang cocok atau sesuai adalah $\operatorname{ARMA}(1,1)$

\section{SIMPULAN}

Tinggi muka air sungai bengawan solo untuk periode Januari - Februari 2017, mengikuti model ARMA(1,1), karena terbukti stasioner terhadap rata-rata tetapi memiliki variansi data yang tidak konstan, sehingga untuk penelitian selanjutnya akan lebih baik jika terdapat model variansi data menggunakan GARCH model ataupun TARCH model. Data runtun waktu adalah sulit untuk dimodelkan karena fluktuasi data dipengaruhi oleh banyak faktor sesuai dengan karakteristik data masing-masing. Oleh karena itu pada penulisan selanjutnya, hal yang dapat dikembangkan dengan model lain seperti TGARCH, MGARCH, dan APARCH. Model tersebut merupakan model yang sesuai untuk data runtun waktu yang bersifat asimetris

\section{DAFTAR PUSTAKA}

Asdak, C. (2010). Hidrologi dan Pengelolaan Daerah Aliran Sungai. Yogyakarta: Gadjah Mada University Press.

Bekti, A. (2011). Model Jaringan Saraf Tiruan RBF-EGARCH untuk Peramalan Data Time Series. Surabaya: Pascasarjana Matematika Institut Teknologi Sepuluh Nopember.

Floros, C. (2005). Forecasting The UK Unemployment Rate: Model Comparisons. International Journal of Applied Econometrics and Quantitative Studies Vol 2, 57-72.

Hartanti, O. D. (2014). Perbandingan Hasil Ramalan. Jurnal Biometrika dan Kependudukan, 143-150.

Kurniawati, O. T. (2016). Analisis Tinggi Muka Air Bengawan Solo Hilir Akibat Adanya Floodway dengan Metode Jaringan Saraf Tiruan. Jurusan Teknologi Pengairan Konsentrasi Sistem Informasi Sumber Daya Air.

Mahmuda, A. F. (2012). Analisis Kuantitas dan Kualitas Air Sungai Pampang Kotamadya Makasar. Makasar: Universitas Hassanudin.

Ruminta. (2008). Model Temporal Curah Hujan dan Debit Sungai Citarum Berbasis ANFIS. Jurnal Sains Dirgantara Vol 6 No 1, 22-38.

Setiawan, A. (2013). Aplikasi Peramalan Penjualan Kosmetik dengan ARIMA. Surabaya: Universitas Kristen Petra.

Suprayogi, H. (2015). Profil Pengelolaan Sumber Daya Air Wilayah Sungai Bengawan Solo. Surakarta: Dinas Pekerjaan Umum.

Tsay, S. R. (2002). Analysis of Financial Time Series. Canada: John Wiley \& Sons Inc. 
Perbandingan Model AR(1), ARMA (1,1), dan ARIMA (1,1,1) pada Prediksi Tinggi Muka Air Sungai Bengawan Solo pada Pos Pemantauan Jurug

Vulandari, R. T. (2014). Model Asimetris EGARCH Volatilitas Return Indeks Saham pada. Seminar Nasional Pendidikan Matematika Ahmad Dahlan (SENDIKMAD 2014) (hal. 1071-1079). Yogyakarta: Universitas Ahmad Dahlan. 